\title{
Semiempirical Study on Electronical Transition Spectra of Ethyl p- methoxycinnamate (EPMS) from Kencur (Kaempferia galanga) for Sunscreen Component
}

\author{
Salmahaminati ${ }^{a}$, and Mokhammad Fajar Pradipta ${ }^{\text {b }}$ \\ ${ }^{a}$ Chemistry Department, Faculty of Mathematics and Natural Sciences \\ Islamic University of Indonesia, Yogyakarta, Indonesia \\ ${ }^{\mathrm{b}}$ Chemistry Department, Faculty of Mathematics and Natural Sciences \\ Gadjah Mada University, Yogyakarta, Indonesia
}

\begin{abstract}
ABSTRAK
Telah dilakukan analisis in silico senyawa tabir surya Etil Para Metoksi Sinamat (EPMS) berdasarkan data transisi elektronik molekul senyawa yang bertujuan untuk memperkirakan EPMS sebagai senyawa tabir surya perisai alami UV-B. Kajian dilakukan dengan membuat model molekul senyawa tabir surya standar Isopropil Para Metoksi Sinamat (IPMS) yang dioptimasi geometri menggunakan metode semiempirik AM1 dan dilanjutkan optimasi analisis spektra transisi elektronik dengan metode ZINDO/S, ZINDO 1, PM3, dan AM1. Analisis spektra transisi elektronik difokuskan pada UV-B (290-315 nm). Hasil kajian secara umum menunjukkan analisis spekta transisi elektronik terbaik adalah ZINDO/s. Perhitungan dengan metode ZINDO/S pada IPMS menunjukkan $\lambda_{\max }$ yaitu 290,77 $\mathrm{nm}$ dan senyawa EPMS diperoleh nilai $\lambda_{\max } 292,41 \mathrm{~nm}$. Hasil ini menunjukkan bahwa EPMS dapat dimanfaatkan sebagai perisai alami $U V-B$.
\end{abstract}

Kata Kunci : tabir surya, transisi elektronik, EPMS, IPMS, AM1, ZINDO/S

\begin{abstract}
In silico analysis of sunscreen compound, Ethyl p-methoxycinnamate, has been done. The aim of the study is to estimate Ethyl p-methoxycinnamate (EPMS) as sunscreen compound or as a natural shield UV-B. The calculation procedure was done as geometry structure optimization on Isopropyl p-methoxycinnamate (IPMS) as standard sunscreen compound by semiempirical method, AM1 and followed by optimized electronic transition spectral analysis that was calculated by ZINDO/S, ZINDO 1, PM3, and AM1. Analysis of the theoretical spectra was focused in the UV-B (290-315 nm). The results of study showed that the best electronic spectral analysis was ZINDO/S. The electronic transition spectra of IPMS give $\lambda_{\max }$ $290.77 \mathrm{~nm}$ and EPMS give $\lambda_{\max } 292.41 \mathrm{~nm}$. These results indicate that the EPMS could be utilized as sunscreen compound of $U V-B$.
\end{abstract}

Key Words: sunscreen, electronical transition, EPMS, IPMS, AM1, ZINDO/S

Semiempirical Study on Electronical Transition Spectra of Ethyl p-methoxycinnamate (EPMS) from Kencur (Kaempferia galanga) for Sunscreen Component

(Salmahaminati dan Mokhammad Fajar Pradipta) 


\section{Pendahuluan}

Riset pengembangan produk senyawa tabir surya saat ini banyak dilakukan dalam rangka menemukan senyawa baru berkhasiat baik dan tidak menyebabkan efek samping pada pemakai. Senyawa tabir surya adalah senyawa yang dapat melindungi kulit dari pengaruh sinar ultraviolet (UV) yang dipancarkan dari matahari. Mekanisme perlindungan senyawa tabir surya adalah penyerapan energi sinar UV yang digunakan untuk eksitasi keadaan elektronik senyawa. Sinar UV dapat digolongkan menjadi tiga bagian menurut panjang gelombang dan efek yang ditimbulkannya terhadap kulit. Efek sinar seperti dalam Tabel 1 (Walters dkk., 1997) dapat terjadi jika kontak antara intensitas sinar UV dengan kulit berlebihan.

Tabel 1. Tabel Klasifikasi sinar ultraviolet

\begin{tabular}{|ccl|}
\hline $\begin{array}{c}\text { Golon } \\
\text {-gan }\end{array}$ & $\begin{array}{c}\text { Daerah } \\
\text { Panjang } \\
\text { Gelombang } \\
\text { (nm) }\end{array}$ & Efek terhadap Kulit \\
\hline UV-C & $100-290$ & $\begin{array}{l}\text { Berbahaya, tetapi } \\
\text { diserap oleh lapisan } \\
\text { ozon di atmosfer. } \\
\text { Efek pada daerah } \\
\text { eritrema yaitu } \\
\text { menyebabkan kulit } \\
\text { terbakar, penuaan } \\
\text { dini. }\end{array}$ \\
& $290-315$ & $\begin{array}{l}\text { Kurang berbahaya, } \\
\text { tetapi dapat } \\
\text { menyebabkan } \\
\text { pigmentasi kulit } \\
\text { menjadi kemerahan. }\end{array}$ \\
\hline
\end{tabular}

Sinar UV-C yang sangat berbahaya bagi kulit sebenarnya dapat diserap lapisan ozon di atmosfer. Namun demikian seiring menipisnya lapisan ozon membuat sinar UV$\mathrm{C}$ ini mampu menembus ke permukaan bumi sehingga mengakibatkan meningkatnya kasus kanker kulit (Walters dkk., 1997).

Senyawa tabir surya dapat dibedakan menjadi dua bagian menurut jenis perlindungannya yakni tabir surya UV-A dan tabir surya UV-B, senyawa tabir surya UV-A mampu melindungi kulit dari pigmentasi sedangkan senyawa tabir surya UV-B melindungi kulit dari eritrema (Walters dkk., 1997).

Senyawa tabir surya sendiri dikelompokkan menjadi dua kelompok yaitu senyawa tabir surya organik (chemical sunscreen) dan senyawa tabir surya anorganik (physical sunscreen) (Larsen dkk., 2006). Senyawa-senyawa tabir surya organik umumnya mempunyai inti benzena yang tersubstitusi pada posisi orto atau para yang terkonjugasi dengan gugus karbonil (Finnen, 1987) dan umumnya berupa turunan senyawa asam salisilat (Xi dkk., 2015). Senyawa-senyawa tabir surya organik tersebut antara lain 2-etilheksil salisilat, oksibenzon, oktil p-metoksisinamat, oktil dimetoksi PABA, 2-etilheksil- $p$ metoksisinamat, oktokrilen, dan homosalat,

Semiempirical Study on Electronical Transition Spectra of Ethyl p-methoxycinnamate (EPMS)

from Kencur (Kaempferia galanga) for Sunscreen Component

(Salmahaminati dan Mokhammad Fajar Pradipta) 
seperti pada Gambar 1. Sedangkan senyawasenyawa tabir surya anorganik misalnya $\mathrm{ZnO}, \mathrm{MgO}, \mathrm{CaCO}_{3}$ dan TiO. Senyawa tabir surya anorganik tidak banyak digunakan secara luas karena selain memiliki resiko alergi yang tinggi dan berbahaya bagi kulit, senyawa ini umumnya dipakai dalam konsentrasi yang besar yaitu 10-100\%.<smiles>COc1ccc(C(=O)c2ccccc2)c(O)c1</smiles><smiles>CCCCCCC(C)COC(=O)c1ccccc1O</smiles>

2-etilfeks il salis ilat<smiles>CCCCCCCC(C)OC(=O)c1ccccc1O</smiles>

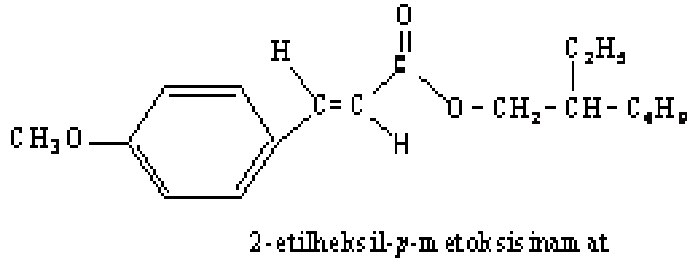

( $\left.\mathrm{C} \mathrm{H}_{3}\right)_{2} \mathrm{H}$

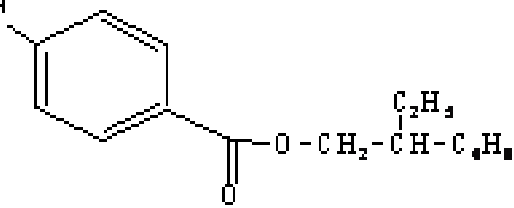

Ohtil dim etoksi PABA<smiles>CCCCCCCC(=O)OCCc1ccc(OC)cc1</smiles>

Oktil $y$-m etok sis inam at

Gambar 1. Contoh senyawa tabir surya organik (Fessenden dan Fessenden, 1990)

Tanaman kencur (Kaempferia galanga) merupakan salah satu tanaman yang berpotensi sebagai bahan sumber senyawa tabir surya organik. Kandungan EPMS dalam rimpang tanaman ini dapat berfungsi sebagai perisai alami sinar UV-B. Tanaman yang termasuk dalam divisi Spermatophyta, sub divisi Angiosperma, kelas Monocotyledonea, bangsa Scitamineae, suku jahe-jahean (Zingiberaceae), marga Kaempferia dan jenis Kaempferia galanga $L$ ini selain digunakan sebagai bumbu masak juga dapat digunakan sebagai obat-obatan tradisional karena dapat meredakan bengkakbengkak, batuk, penambah nafsu makan dll.

Semiempirical Study on Electronical Transition Spectra of Ethyl p-methoxycinnamate (EPMS) from Kencur (Kaempferia galanga) for Sunscreen Component 
Dalam bidang kosmetika tradisional digunakan sebagai bahan ramuan bedak dingin beras kencur (Taufikurromah dkk., 2008). Senyawa tabir surya berbahan EPMS dari rimpang kencur lebih aman dipakai dan lebih murah dibandingkan dengan zat kimiawi, terutama bagi kulit sensitif (Dewi dkk.,2008). Kosmetika berbahan kimia berpeluang lebih besar mengakibatkan iritasi maupun kerusakan pada kulit.

Kemampuan senyawa tabir surya dalam melindungi kulit dari paparan sinar UV identik dengan panjang gelombang serapan maksimum. Hal tersebut bergantung pada stuktur elektronik setiap senyawa (Tahir dkk., 2005). Senyawa berpotensi tabir surya sebagian besar merupakan senyawa organik yang memiliki gugus-gugus kromofor yang mampu menyerap sinar UV. Kemampuan ini disebabkan transisi elektronik dalam molekul tabir surya di mana energi transisi tersebut setara dengan energi sinar UV. Untuk menentukan besarnya panjang gelombang maksimum dapat ditentukan baik secara eksperimen maupun secara komputasi dengan menentukan spektra transisi elektronik senyawa. Hasil perbandingan yang dilakukan oleh Walters dkk. menunjukkan ternyata terdapat perbedaan antara panjang gelombang eksperimen dan panjang gelombang hasil prediksi secara kimia komputasi. Fenomena tersebut menunjukkan adanya perbedaan kondisi antara eksperimen dengan pendekatan kimia komputasi yang dilakukan.

Penelitian ini menggunakan isopropil p-metoksisinamat (IPMS) sebagai standar. Analisis dilakukan terhadap senyawa IPMS yang telah diketahui sebagai perisai UV-B dan memiliki panjang gelombang sekitar 300 nm (Nicholash dkk., 2008), kemudian diterapkan metode yang sesuai pada analisis transisi elektronik untuk senyawa EPMS.

\section{Tujuan Penelitian}

Menerapkan metode pendekatan kimia pemodelan untuk analisis transisi elektronik senyawa EPMS pada rimpang kencur sebagai bahan tabir surya pada industri kosmetik.

\section{Metode Penelitian}

\section{Peralatan}

Peralatan kimia komputasi yang digunakan berupa satu unit komputer dengan spesifikasi: Prosesor Pentium 41,4 GHz, memori SDRAM 256 MB, dan HD 20 GB, serta perangkat lunak kimia komputasi HyperChem versi 8.0 berbasis Windows.

\section{Obyek Penelitian}

Menggunakan IPMS dan EPMS sebagai model senyawa, dengan struktur

Semiempirical Study on Electronical Transition Spectra of Ethyl p-methoxycinnamate (EPMS) from Kencur (Kaempferia galanga) for Sunscreen Component 
senyawa seperti terlihat pada Gambar 2 dan Gambar 3.

\section{Prosedur penelitian}

Analisis dilakukan dengan mencari struktur energi total terendah melalui optimasi geometri menggunakan metode semiempirik AM1 dan penentuan polarisabilitas. Analisis transisi elektronik dilakukan dengan cara mempelajari panjang gelombang dengan membandingkan metode ZINDO/s, ZINDO 1, PM3, dan AM1.

\section{Optimasi Geometri dengan metode AM1}

Setiap model senyawa dibuat struktur 2D dengan paket perangkat lunak HyperChem versi 8.0 selanjutnya dilengkapi dengan atom hidrogen pada setiap atom untuk melengkapi struktur sebenarnya dan kemudian dibentuk menjadi struktur 3D. Proses dilanjutkan dengan optimasi geometri struktur berupa minimasi energi struktur untuk memperoleh konformasi struktur terstabil dengan metode semiempirik AM1. Batas konvergensi ditentukan berdasarkan pengamatan orientasi yaitu telah mencapai batas gradien sekawan (perubahan energi sebesar $0,01 \mathrm{kkal} /(\AA \AA . m o l)$. Metode optimasi berdasarkan metode Polak-Ribiere. Data hasil perhitungan yang meliputi data yang mengenai energi dan stuktur elekronik senyawa direkam pada menu log.

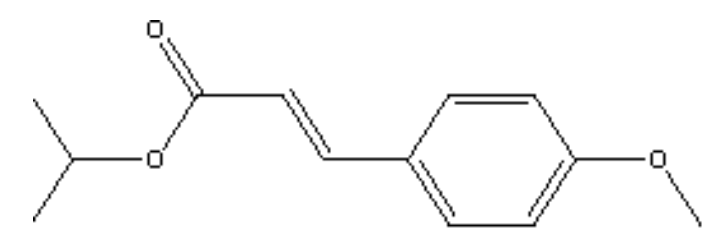

Gambar 2. Struktur senyawa tabir surya IPMS

\section{Penentuan Polarisabilitas}

Struktur senyawa IPMS dan EPMS yang telah dilakukan geometri optimasi akan terstabilkan dan dilakukan penentuan polarisabilitasnya.

Penentuan spektra elektronik dengan ZINDO/S, ZINDO 1, PM3 , dan AM1.

Stuktur hasil optimasi geometri menghasilkan struktur senyawa IPMS terstabilkan, selanjutnya untuk mengetahui spektra transisi elektronik senyawa dilakukan perhitungan single point menggunakan metode semiempirik ZINDO/s. Perhitungan dilakukan dengan menjalankan secara bersamaan Restricted Hatree-Fock (RHF) dengan Configuration Interaction (C1)-single excited dengan batasan orbital HOMO dan LUMO masingmasing 7. Setelah perhitungan dijalankan akan dihasilkan spektrum transisi elektronik yang menampilkan panjang gelombang dan intensitas serapan berupa kekuatan osilasi dalam bentuk diagram spektra yang diskontinyu. Data hasil perhitungan di simpan dalam file log dan dilakukan kembali dengan metode ZINDO 1, PM3, AM1. Hasil

Semiempirical Study on Electronical Transition Spectra of Ethyl p-methoxycinnamate (EPMS) from Kencur (Kaempferia galanga) for Sunscreen Component 
analisis dilakukan tinjauan terhadap nilai transisi elektronik yang berada pada serapan sinar UV-B (290-315 nm). Pemilihan nilai panjang gelombang ditentukan dengan intensitas serapan yang tinggi kemudian dijadikan acuan aktivitas teoritik senyawa tabir surya dan diterapkan metode yang nilai panjang gelombang sesuai dengan eksperimen untuk menguji spektra transisi elektronik senyawa EPMS.

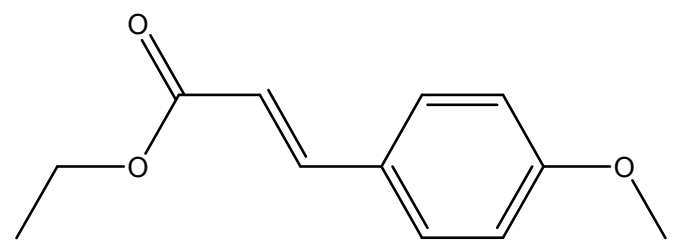

Gambar 3. Struktur senyawa tabir surya EPMS

\section{Pembahasan}

Pemodelan senyawa IPMS dan EPMS dengan metode semiempirik AM1 (Austin Model 1) dan nilai batas gradien energi optimasi geometri sebesar 0,01 kkal/(Å.mol). Hal ini dilakukan karena pertimbangan bahwa senyawa tabir surya merupakan senyawa organik yang molekulmolekulnya tersusun atas atom-atom yang telah diparameterisasi dengan baik oleh metode semiempirik AM1, selain itu dari penelitian-penelitian terdahulu mengenai perhitungan spektra elektronik menunjukkan metode AM1 memberikan optimasi geometri yang lebih baik.
Senyawa tabir surya memiliki kemampuan menyerap sinar UV pada panjang gelombang tertentu sebagai akibat adanya gugus-gugus fungsional yang dapat menghasilkan transisi elektronik yang besar energinya sesuai dengan rentang energi sinar UV. Tiap transisi memiliki intensitas yang berbeda dalam menyerap sinar UV dan yang menjadi acuan dari kemampuan senyawa tabir surya dalam menyerap sinar UV adalah panjang gelombang serapan sinar UV dengan intensitas maksimal atau yang biasa disebut panjang gelombang serapan maksimal.

Senyawa IPMS yang telah diketahui sebagai perisai UV-B dan memiliki panjang gelombang sekitar $300 \mathrm{~nm}$ seperti terlihat pada Gambar 4. (Nicholash dkk., 2008).

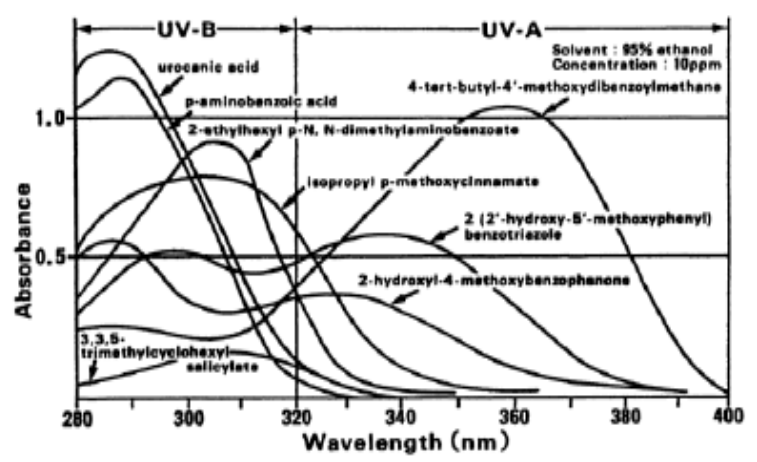

Gambar 4. Spektrum absorbsi senyawasenyawa pada rentang UV-A dan UV-B

Setelah dilakukan analisis spektra transisi elektronik dengan berbagai macam metode diperoleh hasilnya sebagai berikut :

Tabel 2. Tabel pemilihan metode komputasi senyawa IPMS

Semiempirical Study on Electronical Transition Spectra of Ethyl p-methoxycinnamate (EPMS) from Kencur (Kaempferia galanga) for Sunscreen Component 


\begin{tabular}{|l|l|l|}
\hline Metode & $\begin{array}{c}\text { Panjang } \\
\text { Gelombang } \\
(\mathrm{nm})\end{array}$ & $\begin{array}{c}\text { Intensitas } \\
\text { maksimal } \\
(\mathrm{I})\end{array}$ \\
\hline AM1 & 217,56 & 0,641 \\
PM3 & 220,32 & 0,589 \\
ZINDO/s & 290,77 & 0,599 \\
ZINDO 1 & 151,19 & 1,780 \\
\hline
\end{tabular}

Pada data analisis spektra transisi elektronik di atas menunjukkan bahwa metode ZINDO/s merupakan metode yang paling sesuai. Hal ini disebabkan karena nilai panjang gelombang dengan intensitas maksimal 0,599 adalah 290,77 nm, sehingga panjang gelombang tersebut masuk pada rentang UV-B (290-315 nm). Jika dibandingkan hasil teori spektra menggunakan metode ZINDO/s dengan hasil eksperimen (2) ternyata menunjukkan kesesuaian bahwa senyawa IPMS merupakan senyawa tabir surya UV-B yang memiliki panjang gelombang sekitar $300 \mathrm{~nm}$.

Senyawa IPMS yang merupakan senyawa tabir surya ternyata memiliki kemampuan menyerap sinar UV-B dengan panjang gelombang tertentu sebagai akibat adanya gugus-gugus fungsional yang dapat menghasilkan transisi elektronik. Spektra transisi elektronik dari perhitungan semiempirik ini memiliki sifat yang diskontinyu.

Spektra diskontinyu ini terjadi karena dalam perhitungan kimia komputasi senyawa diasumsikan dalam keadaan gas murni, sehingga tidak ada pengaruh dari senyawa lain dan transisi elektronik hanya berlaku secara terkuantumkan yakni dari suatu lintasan ke lintasan lainnya. Spektra transisi elektronik hasil pengukuran secara semiempirik dengan metode ZINDO/s disajikan pada gambar 5. Pada metode ZINDO/s menggunakan pendekatan RHF dengan menjalankan perhitungan CI-single excited yang diukur adalah masing-masing selisih energi dari tiap keadaan transisi yang kemudian intensitasnya dihitung menggunakan persamaan tertentu. Hal ini menyebabkan data hasil perhitungannya menjadi data yang bersifat insidensial pada tingkat energi tertentu dan menjadi ketidakkontinyuan data.

Nilai panjang gelombang yang dihasilkan oleh optimasi geometri menggunakan metode Austin Model 1 yang dilanjutkan dengan perhitungan spektra transisi elektronik menggunakan metode semiempirik ZINDO/s, menunjukkan bahwa hasilnya mendekati eksperimen.

Semiempirical Study on Electronical Transition Spectra of Ethyl p-methoxycinnamate (EPMS) from Kencur (Kaempferia galanga) for Sunscreen Component 


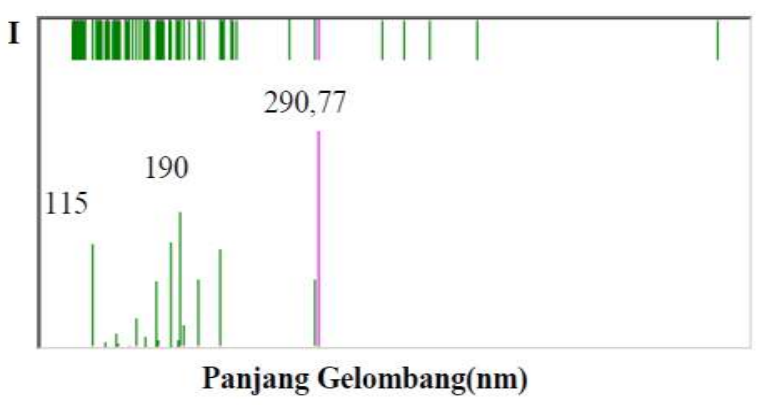

Gambar 5. Spektra serapan senyawa (nm) IPMS dengan metode ZINDO/s

Dari analisis stuktur kimia senyawa IPMS terlihat ketersediaan gugus-gugus kromofor tak terkonjugasi sederhana disajikan pada gambar 2. Masing-masing memiliki jenis transisi elektron dan panjang gelombang serapan yang berbeda-beda. Gugus kromofor tak terkonjugasi tersebut adalah:

1. $\mathrm{C}=\mathrm{O}$ transisi $\mathrm{n}$ ke $\pi^{*}$, panjang gelombang $300 \mathrm{~nm}$.

2. $\mathrm{C}=\mathrm{O}$ transisi $\mathrm{n}$ ke $\sigma^{*}$, panjang gelombang $190 \mathrm{~nm}$.

3. O transisi $\mathrm{n}$ ke $\sigma^{*}$, panjang gelombang $185 \mathrm{~nm}$.

Setelah dilakukan perhitungan panjang gelombang senyawa IPMS, hasil dari pemilihan metode akan digunakan untuk menganalisis senyawa EPMS. Metode komputasi yang digunakan adalah metode ZINDO/s. Pada pengujian polarisabilitas senyawa IPMS diperoleh nilai kepolarannya adalah 24,45 $\AA^{3}$ sedangkan nilai kepolaran senyawa EPMS adalah 22,61 $\AA^{3}$. Dari hasil analisis tersebut menunjukkan nilai kepolaran senyawa EPMS ternyata lebih rendah dari senyawa IPMS, namun perbedaan kepolaran hanya menunjukkan kelarutan senyawa tersebut dalam air.

Pada analisis spektra transisi elektronik dengan perhitungan panjang gelombang senyawa EPMS menggunakan metode ZINDO/s, diperoleh nilai panjang gelombang 292,41 $\mathrm{nm}$ pada intensitas maksimal 0,919 (disajikan pada Gambar 6). Dari hasil nilai panjang gelombang tersebut diperoleh bahwa senyawa EPMS merupakan senyawa tabir surya yang menyerap sinar UV-B pada rentang sinar 290-315 nm.

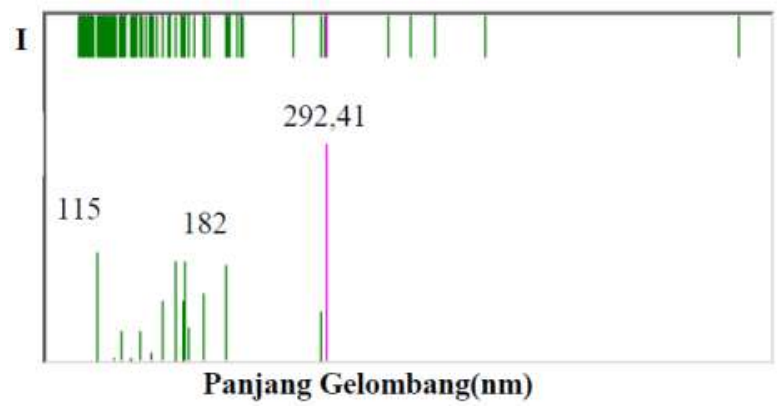

Gambar 6. Spektra serapan senyawa (nm) EPMS dengan metode ZINDO/s

Dari analisis stuktur kimia senyawa EPMS, terlihat ketersediaan gugus-gugus kromofor tak terkonjugasi sederhana disajikan pada Gambar 6. Masing-masing memiliki jenis transisi elektron dan panjang gelombang serapan yang berbeda-beda seperti pada senyawa IPMS.

Semiempirical Study on Electronical Transition Spectra of Ethyl p-methoxycinnamate (EPMS) from Kencur (Kaempferia galanga) for Sunscreen Component 
Jika dibandingkan senyawa IPMS pada nilai panjang gelombangnya, senyawa EPMS memiliki panjang gelombang yang relatif sedikit lebih tinggi dari panjang gelombang IPMS. Senyawa EPMS merupakan senyawa tabir surya UV-B. Dan dari hasil pengukuran kepolarannya diperoleh bahwa senyawa EPMS memiliki nilai kepolarannya lebih rendah menunjukkan senyawa ini lebih kurang larut di dalam air.

IPMS merupakan senyawa tabir surya yang selama ini diimpor dari luar negeri (Nicholash, 2008) untuk keperluan pembuatan kosmetika di Indonesia, ternyata dapat di gantikan oleh EPMS sebagai hasil isolasi dari rimpang kencur. Manfaat yang diperoleh pada kalangan industri kosmetik Indonesia adalah kita dapat membeli bahan kosmetik yang lebih murah dibandingkan bila harus mengimpor bahan kosmetik tersebut.

\section{Kesimpulan}

Desain senyawa tabir surya dapat dilakukan dengan menggunakan metode kimia komputasi melalui pendekatan perhitungan transisi elektronik hasil perhitungan semiempirik molekul metode ZINDO/s. Senyawa EPMS merupakan senyawa tabir surya yang dapat menyerap UV-B.

\section{Pustaka}

Aryani, D., 2008, Tabir Surya Dari Rimpang Kencur, http://www.kompas.com/read/xml/20 08/04/08/17181934 Diakses pada 30 juni 2009

Fessenden, R.J., dan Fessenden, J.S., 1990, Organic Chemistry, edisi 4, University of Montana, California.

Finnen, M.J., Skin Metabolism by Oxidation and Conjugation, J. Pharmacol. Skin, 1, 130-131

Larsen, dan Hans, R., 2006, Sunscreen and Cancer,http://www.yourhealthbase.co m., Diakses pada 24 Januari 2006.

Nicholas J,Lowe. Nadim A. Shaath dan Madhu A,Pathak .2008.Suncreens http://books.google.com/books?id=kv 67G9uYC28C\&pg=PA241\&lpg=PA $241 \& d q=$ suncreen + industry + in + japa n\&source $=$ bl\&ots $=$ DAEYXISIiw\&si $\mathrm{g}=\mathrm{zJ}$ 8LFRNkrMi62OB_VdN1r9L2h1 $\mathrm{s} \& \mathrm{hl}=\mathrm{en} \& \mathrm{ei}=\mathrm{z} 7 \mathrm{~B}$ SuPDDYGXkQW vkfHfAg\&sa $=X \&$ oi $=$ book_result\&ct $=$ result $\&$ resnum $=1 \# \mathrm{v}=$ onepage $\& \mathrm{q}=\&$ $\mathrm{f}=$ false. Diakses pada 25 juni 2009

Rahmi dan Tahir ,L., 2005, Analisis In Silico Senyawa Tabir Surya Turunan Oksibenzon dengan Pendekatan Perhitungan Orbital Molekul ZINDO/s Jurnal Farmasi Indonesia, 2, 1, 1-11.

Sastroamidjojo, H., 1991, Spektroskopi, Liberty, Yogyakarta.

Taufikurohmah, T., Rusmini dan Nurhayati. 2008, Pemilihan Pelarut dan Optimasi Suhu Pada Isolasi Senyawa Etil Para Metoksi Sinamat (EPMS) dari Rimpang Kencur Sebagai Bahan Tabir Surya Pada Industri Kosmetik, http://www. bincang-bincang kimia; artikel penelitian.com. Diakses pada 30 juni 2009

Walters, C., Keeney, A., Wigal, C., dan Cornelius, R.. 1997. The Spectrophotometric Analysis and

Semiempirical Study on Electronical Transition Spectra of Ethyl p-methoxycinnamate (EPMS) from Kencur (Kaempferia galanga) for Sunscreen Component 
Modelling of Sunscreen, J. Chem. Educ., 74, 99-102
Xi, K., Shin, S.B., dan Hu, H., 2015, Cosmetic Use of Salicilic Acid Derrivatives, US Patent.

Semiempirical Study on Electronical Transition Spectra of Ethyl p-methoxycinnamate (EPMS) from Kencur (Kaempferia galanga) for Sunscreen Component 